\title{
Article \\ Serum TARC Levels in Patients with Systemic Sclerosis: Clinical Association with Interstitial Lung Disease
}

\author{
Ai Kuzumi ${ }^{1}$, Ayumi Yoshizaki ${ }^{1, *}$, Satoshi Ebata ${ }^{1}$, Takemichi Fukasawa ${ }^{1}$ (D, Asako Yoshizaki-Ogawa ${ }^{1}$, \\ Yoshihide Asano ${ }^{1}$ (D) Koji Oba ${ }^{2}$ (D) and Shinichi Sato ${ }^{1}$
}

1 Department of Dermatology, Graduate School of Medicine, The University of Tokyo, Tokyo 113-8655, Japan; KUZUMIA-DER@h.u-tokyo.ac.jp (A.K.); EBATAS-DER@h.u-tokyo.ac.jp (S.E.); FUKASAWAT-DER@h.u-tokyo.ac.jp (T.F.); YOSHIZAKIA-DER@h.u-tokyo.ac.jp (A.Y.-O.); ASANOY-DER@h.u-tokyo.ac.jp (Y.A.); SATOS-DER@h.u-tokyo.ac.jp (S.S.)

2 Department of Biostatistics, School of Public Health, Graduate School of Medicine, The University of Tokyo, Tokyo 113-8655, Japan; oba@epistat.m.u-tokyo.ac.jp

* Correspondence: ayuyoshi@me.com; Tel.: +81-3-5800-8661; Fax: +81-3-3814-1503

Citation: Kuzumi, A.; Yoshizaki, A.; Ebata, S.; Fukasawa, T; Yoshizaki-Ogawa, A.; Asano, Y.; Oba, K.; Sato, S. Serum TARC Levels in Patients with Systemic Sclerosis: Clinical Association with Interstitial Lung Disease. J. Clin. Med. 2021, 10, 660 https://doi.org/10.3390/jcm10040660

Academic Editor: Keiichi Yamanaka Received: 30 December 2020

Accepted: 5 February 2021

Published: 9 February 2021

Publisher's Note: MDPI stays neutral with regard to jurisdictional claims in published maps and institutional affiliations.

Copyright: (c) 2021 by the authors. Licensee MDPI, Basel, Switzerland. This article is an open access article distributed under the terms and conditions of the Creative Commons Attribution (CC BY) license (https:// creativecommons.org/licenses/by/ $4.0 /)$.

\begin{abstract}
Systemic sclerosis (SSc) is a multisystem fibrotic disorder with autoimmune background. Accumulating evidence has highlighted the importance of T helper (Th) 2 cells in the pathogenesis of SSc and its complications. Because thymus and activation-regulated chemokine (TARC) is a potent chemoattractant for Th2 cells, we measured serum TARC levels in SSc patients and analyzed their correlation with interstitial lung disease (ILD), a major complication of SSc. Serum TARC levels were significantly elevated in patients with SSc, especially in those with the diffuse subtype, compared with healthy controls. In particular, dcSSc patients with SSc-associated ILD (SSc-ILD) showed higher TARC levels than those without SSc-ILD. However, there was no significant correlation between serum TARC levels and pulmonary function in SSc patients. Serum TARC levels did not correlate with serum levels of interleukin-13, an important Th2 cytokine, either. Furthermore, in the longitudinal study, serum TARC levels did not predict the onset or progression of SSc-ILD in patients with SSc. These results were in contrast with those of KL-6 and surfactant protein D, which correlated well with the onset, severity, and progression of SSc-ILD. Overall, these results suggest that serum TARC levels are not suitable for monitoring the disease activity of SSc-ILD.
\end{abstract}

Keywords: systemic sclerosis; $\mathrm{T}$ helper 2; thymus and activation-regulated chemokine; interstitial lung disease; pulmonary function

\section{Introduction}

Systemic sclerosis (SSc) is a progressive connective tissue disease in which excessive fibrosis of the skin and internal organs leads to diverse clinical manifestations that are highly distressing and often life-threatening [1,2]. Although the pathogenesis of SSc still remains unclear, various immunological abnormalities have been identified in SSc, indicating the autoimmune nature of the disease [3,4]. In particular, abnormalities of $\mathrm{T}$ cells have been extensively studied in both patients and animal models of SSc [5,6]. Notably, T-cell immune responses in SSc are heavily skewed toward T helper (Th) 2 with increased production of Th2 cytokines such as interleukin IL-4 and IL-13 [7-9]. Th2 cells drive the pathological cascade of SSc through multiple mechanisms [10]. Indeed, various cytokines and chemokines that are involved in activation, migration, and differentiation of Th2 cells have been implicated in the development of SSc [11-15].

Thymus and activation-regulated chemokine (TARC), also known as CC chemokine ligand 17 , is a member of the CC chemokine group that is constitutively expressed in the thymus and is produced by keratinocytes, endothelial cells, bronchial epithelial cells, and other cell types [16]. TARC is a potent and selective chemoattractant for T cells expressing CC chemokine receptor 4 (CCR4) [17]. Because CCR4 is preferentially expressed 
on Th2 cells, TARC has been associated with Th2-dominant skin diseases, including atopic dermatitis, bullous pemphigoid, and cutaneous T-cell lymphoma [18-20]. For instance, TARC recruits CCR4 $4^{+}$Th 2 cells into lesional skin in atopic dermatitis, where serum TARC levels are used as a sensitive biomarker for monitoring disease activity [21,22].

In recent years, TARC has also been implicated in interstitial lung disease (ILD), a common and severe complication of SSc. ILD is a group of inflammatory and fibrotic lung diseases with different etiologies such as infection, malignancy, drug-induced, and connective tissue diseases [23,24]. Yamane et al. have shown that serum TARC levels are elevated in patients with non-small cell lung cancer associated with ILD compared with patients without ILD [25]. They have also reported that TARC is a potential diagnostic marker for drug-induced ILD in the treatment of malignant lymphoma [26]. In the context of ILD caused by connective tissue diseases, serum TARC levels are increased in patients with dermatomyositis-associated ILD [27].

A previous study has demonstrated that serum TARC levels are elevated in SSc patients [28], which is in line with the Th2 dominance in SSc and the close association between TARC and Th2 immune responses. Accumulating evidence has shown that Th2 cells and Th2 cytokines are also critically involved in the development of SSc-associated ILD (SSc-ILD) $[29,30]$. However, there were no statistically significant differences in serum TARC levels between patients with SSc-ILD and those without SSc-ILD in the above study [28]. Due to the heterogenous and progressive nature of the disease, cytokine and chemokine profiles in SSc can vary by patient population, especially depending on the progression of SSc [31,32]. Therefore, to assess the involvement of TARC in SSc-ILD, it is important to examine TARC expression according to the severity and disease activity of SSc-ILD. However, there have been no studies investigating the association between serum TARC levels and the progression of SSc-ILD.

Here, to evaluate the relevance of TARC in SSc-ILD, we examined serum TARC levels in SSc patients and analyzed their correlations with clinical parameters in the longitudinal study.

\section{Experimental Section}

\subsection{Patients}

Serum samples were obtained from 74 Japanese SSc patients (36 women, 8 men; age [mean $\pm \mathrm{SD}$ ], $46.0 \pm 16.2$ years; disease duration, $1.46 \pm 1.37$ years) and 14 healthy controls (11 women, three men; age, $45.4 \pm 10.8$ years) at their first visit after getting written informed consent. All patients fulfilled the ACR/EULAR classification criteria for SSc [33]. Patients treated with corticosteroids or other immunosuppressants prior to their first visit were excluded. SSc patients were categorized by LeRoy's classification system [34]: 55 diffuse cutaneous SSc (dcSSc) patients (age, $44.6 \pm 16.6$ years; disease duration, $1.30 \pm 1.33$ years) and 19 limited cutaneous SSc (lcSSc) patients (age, $48.9 \pm 15.4$ years; disease duration, $1.83 \pm 1.47$ years). In a retrospective longitudinal study, serum samples from 52 patients who had SSc-ILD at their first visit were obtained after the short-time follow-up period of $6.96 \pm 1.60$ months. The whole study was approved by the ethics committee of the University of Tokyo Graduate School of Medicine.

\subsection{Clinical Assessment}

Complete medical histories, physical examination, and laboratory tests were conducted on all patients at their first visit and at the end of the follow-up period. Disease onset was defined as the first clinical event of SSc other than Raynaud's phenomenon. Disease duration was calculated as the interval between the onset of SSc and the time of blood sampling at their first visit. Skin thickness was measured by the modified Rodnan total skin thickness score as previously described [35]. The percentage of predicted forced vital capacity (\%FVC) and the percentage of predicted diffusing capacity for carbon monoxide (\%DLco) were measured by a pulmonary function test. Organ involvement was defined as follows: ILD = ground-glass opacity and/or reticular pattern on high-resolution 
computed tomography; pulmonary hypertension = right ventricular systolic pressure of $35 \mathrm{mmHg}$ or higher on echocardiogram [36]; esophagus = gastroesophageal reflux disease detected at upper gastrointestinal endoscopy; kidneys = malignant hypertension and $/$ or rapidly progressive renal failure.

\subsection{Measurement of Serum TARC and IL-13 Levels}

Serum TARC and IL-13 levels were evaluated using enzyme-linked immunosorbent assay kits (R\&D Systems, Minneapolis, MN, USA). Briefly, microplates coated with antiTARC antibodies or anti-IL-13 antibodies were incubated with serum for $2 \mathrm{~h}$ (for TARC) or $1 \mathrm{~h}$ (for IL-13). Subsequently, the wells were washed and incubated for $1 \mathrm{~h}$ (for TARC) or $30 \mathrm{~min}$ (for IL-13) with horseradish peroxidase-conjugated antibodies against TARC or IL-13. Then, the wells were washed again, supplemented with tetramethylbenzidine, and incubated for $30 \mathrm{~min}$. Finally, sulfuric acid was added to terminate the reaction. The absorbance at $450 \mathrm{~nm}$ was measured. Serum TARC and IL-13 levels were calculated from a standard curve.

\subsection{Statistical Analysis}

Data are presented as means \pm SD. Statistical analysis was performed by MannWhitney U-test for two-group comparison, Fisher's exact probability test for frequency analysis, and Spearman's rank correlation coefficient for clinical correlations. P values less than 0.05 were considered statistically significant. All analyses were performed using GraphPad Prism 7.03 (GraphPad Software, La Jolla, CA, USA).

\section{Results}

\subsection{Serum TARC Levels in Patients with SSc}

Initially, we measured serum TARC levels in 74 SSc patients and 14 healthy controls at their first visit. Serum TARC levels were significantly elevated in SSc patients compared to the healthy controls $(563.4 \pm 381.4 \mathrm{pg} / \mathrm{mL}$ vs. $251.3 \pm 89.4 \mathrm{pg} / \mathrm{mL}, p<0.0001$; Figure 1$)$. Within the SSc subgroups, dcSSc patients showed higher TARC levels $(634.5 \pm 399.1 \mathrm{pg} / \mathrm{mL})$ than the healthy controls $(p<0.0001)$, while there were no statistically significant differences in TARC levels between the lcSSc patients $(357.6 . \pm 277.8 \mathrm{pg} / \mathrm{mL}$ ) and the healthy controls $(p=0.14)$.

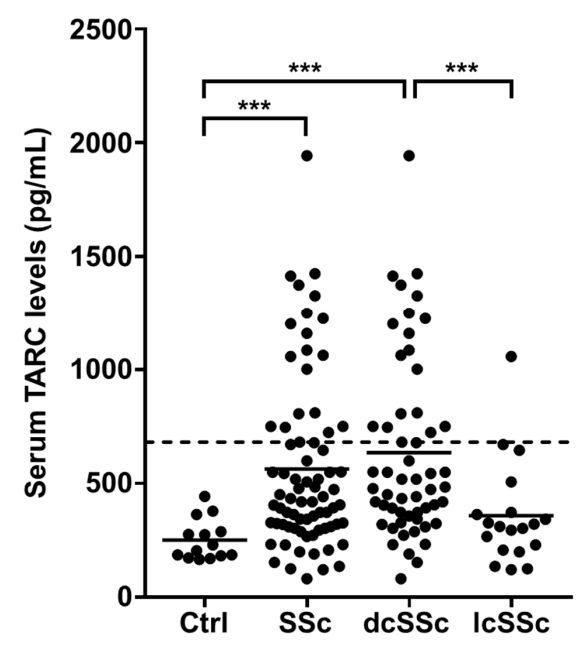

Figure 1. Serum TARC levels in patients with systemic sclerosis (SSc). Serum TARC levels were determined in diffuse cutaneous systemic sclerosis (dcSSc) patients $(n=55)$, limited cutaneous systemic sclerosis (lcSSc) patients $(n=19)$, and healthy controls (Ctrl; $n=14)$ by a specific enzymelinked immunosorbent assay kit. The horizontal lines represent the mean values. The broken line represents the cut-off value (mean $+2 \mathrm{SD}$ of the healthy controls). Mann-Whitney U-test was performed for two-group comparison. ${ }^{* *} p<0.001$. 


\subsection{Clinical Association of Serum TARC Levels in SSc Patients}

Next, clinical features were compared between SSc patients with elevated serum TARC levels and those with normal levels (Table 1). Values more than the mean $+2 \mathrm{SD}$ $(681.3 \mathrm{pg} / \mathrm{mL})$ of the control serum samples were considered elevated. Serum TARC levels were increased in $27.0 \%(20 / 74)$ of SSc patients. Within the SSc subgroups, TARC levels were increased in $34.5 \%(19 / 55)$ of dcSSc patients and $5.2 \%(1 / 19)$ of lcSSc patients. There were no significant differences in sex, age, disease duration, or autoantibody type between patients with elevated TARC levels and those with normal levels. Of note, patients with elevated TARC levels were more frequently categorized as dcSSc than those with normal levels $(95.0 \%$ vs. $66.7 \%, p=0.015)$. Furthermore, patients with elevated TARC levels were more frequently accompanied by SSc-ILD ( $90.0 \%$ vs. $63.0 \%, p=0.025)$. Consistent with this finding, serum TARC levels in SSc patients with ILD were significantly higher compared with those without ILD $(636.1 \pm 412.3 \mathrm{pg} / \mathrm{mL}$ vs. $391.7 \pm 221.0 \mathrm{pg} / \mathrm{mL}$, $p=0.010$; Figure 2). However, there were no significant differences in $\% \mathrm{FVC}$ or $\% \mathrm{DLco}$ between patients with elevated TARC levels and those with normal levels $(p=0.504$ for $\% \mathrm{FVC}$ and $p=0.299$ for \%DLco). Within the SSc subtype, elevated serum TARC levels were associated with SSc-ILD in dcSSc but not in lcSSc patients. Pulmonary hypertension was not associated with the elevated serum TARC levels in either dcSSc or lcSSc patients (Tables S1 and S2). We found no significant differences in other clinical features between SSc patients with elevated and normal TARC levels.

Table 1. Clinical and laboratory features of SSc patients.

\begin{tabular}{cccc}
\hline Clinical and Laboratory Features & \multicolumn{3}{c}{ Serum TARC Levels } \\
\hline & Elevated $(n=20)$ & Normal $(n=54)$ & $p$ values \\
\hline Sex, number of women/men & $18 / 2$ & $48 / 6$ & $>0.999$ \\
Age, mean years \pm SD & $51.6 \pm 15.5$ & $48.9 \pm 17.0$ & 0.601 \\
Disease duration, mean years \pm SD & $3.0 \pm 2.7$ & $3.4 \pm 4.7$ & 0.647 \\
Disease pattern, No. of dcSSc/lcSSc & $19 / 1$ & $36 / 18$ & $0.015 *$ \\
MRSS, mean points \pm SD & $12.5 \pm 7.7$ & $11.5 \pm 8.2$ & 0.480 \\
Autoantibodies & & & \\
Anti-topoisomerase I & $75 \%(15 / 20)$ & $80 \%(43 / 54)$ & 0.753 \\
Anticentromere & $10 \%(2 / 20)$ & $30 \%(16 / 54)$ & 0.126 \\
Anti-RNA polymerase III & $5 \%(1 / 20)$ & $9 \%(5 / 54)$ & $>0.999$ \\
Organ involvement & & & \\
Lung & & & $0.025 *$ \\
ILD & $90 \%(18 / 20)$ & $63 \%(34 / 54)$ & 0.504 \\
FVC, mean \% predicted \pm SD & $85.2 \pm 15.3$ & $89.3 \pm 18.3$ & 0.299 \\
DLco, mean \% predicted \pm SD & $74.4 \pm 23.2$ & $80.0 \pm 20.0$ & 0.569 \\
Pulmonary hypertension & $0 \%(0 / 20)$ & $7 \%(4 / 54)$ & 0.245 \\
Esophagus & $85 \%(17 / 20)$ & $69 \%(38 / 54)$ & 0.470 \\
Kidneys & $5 \%(1 / 20)$ & $2 \%(1 / 54)$ & $>0.999$ \\
Cutaneous symptoms & & & $>0.999$ \\
Raynaud's phenomenon & $95 \%(19 / 20)$ & $91 \%(49 / 54)$ & 0.068 \\
Nail fold bleeding & $60 \%(12 / 20)$ & $61 \%(33 / 54)$ & 0.796 \\
Telangiectasia & $30 \%(6 / 20)$ & $56 \%(30 / 54)$ & 0.411 \\
Pitting scars & $45 \%(9 / 20)$ & $50 \%(27 / 54)$ & $39 \%(21 / 54)$ \\
Digital ulcers & $25 \%(5 / 20)$ & $34)$ & \\
\hline
\end{tabular}

Unless noted otherwise, values are percentages and values in parentheses represent the number of patients. dcSSc, diffuse cutaneous systemic sclerosis; lcSSc, limited cutaneous systemic sclerosis; MRSS, modified Rodnan total skin thickness score; ILD, interstitial lung disease; FVC, forced vital capacity; DLco, diffusing capacity for carbon monoxide. ${ }^{*} p<0.05$ vs. SSc patients with normal serum TARC levels. 


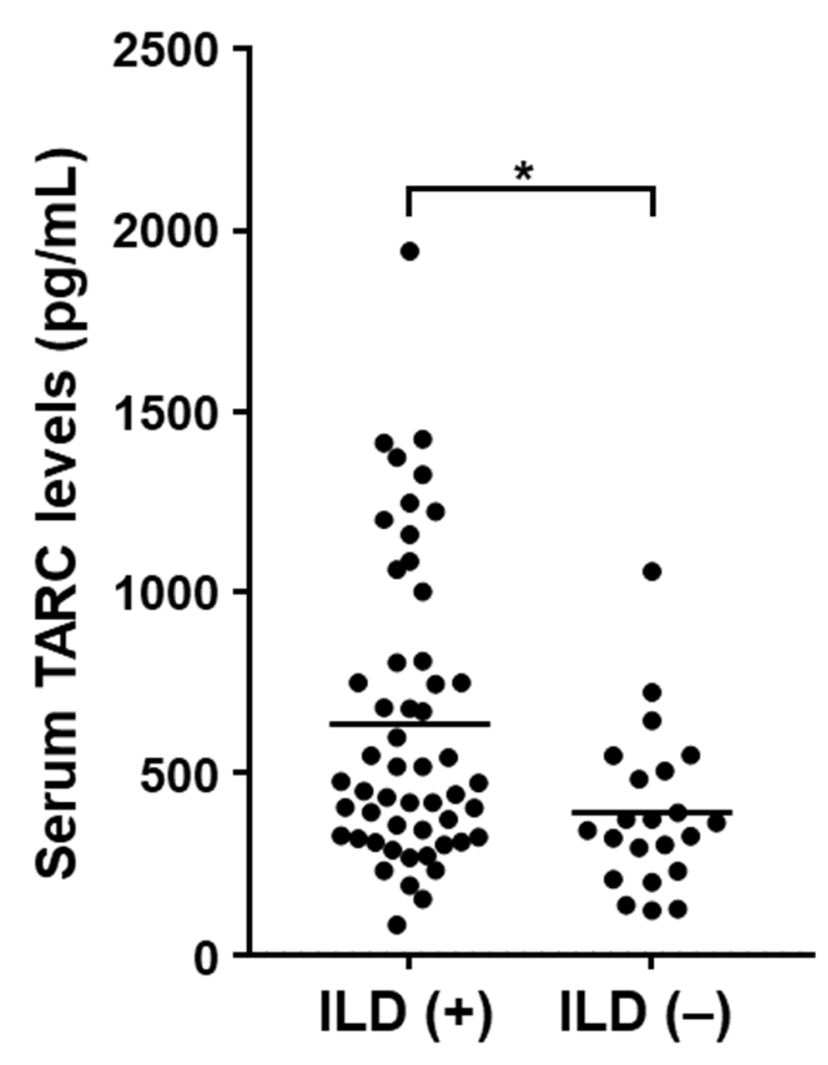

Figure 2. Serum TARC levels in SSc patients with or without SSc-ILD. Serum TARC levels were compared between SSc patients with and without SSc-ILD. Mann-Whitney U-test was performed for two-group comparison. ${ }^{*} p<0.05$.

\subsection{Correlation between Serum TARC Levels and the Severity of SSc-ILD}

Subsequently, we analyzed the correlation between serum TARC levels and pulmonary function in the whole SSc patients. Serum TARC levels did not correlate with \%FVC $(r=-0.0733, p=0.535)$ or $\%$ DLco $(r=-0.0959, p=0.416$; Figure 3$)$. We also examined the correlation of serum levels of KL-6 and surfactant protein-D (SP-D), the conventional biomarker for SSc-ILD [37-41], with pulmonary function. Both KL-6 and SP-D showed significant negative correlation with \%FVC $(r=-0.430, p=0.0001$ for KL-6, $r=-0.531$, $p<0.0001$ for SP-D) and \%DLco $(r=-0.438, p<0.0001$ for KL- $6, r=-0.456, p<0.0001$ for SP-D). These results suggest that serum TARC levels are not associated with the severity of SSc-ILD. Because Th2 immune responses has been implicated in SSc-ILD [29,30], we also measured serum IL-13 levels in the same SSc patient group. However, these was no significant correlation between serum levels of TARC and IL-13 in SSc patients $(r=0.153$, $p=0.192$ Figure S1). Together with the lack of correlation between serum TARC levels and the severity of SSc-ILD, this result suggests that serum TARC levels in SSc patients might not necessarily reflect Th2 immune responses nor their contribution to SSc-ILD.

3.4. Correlation between Serum TARC Levels at the First Visit and the Development of SSc-ILD during the Follow-up Period

Next, we investigated whether serum TARC levels in SSc patients at their first visit would predict the newly onset of SSc-ILD during the follow-up period (6.96 \pm 1.60 months). For this purpose, 22 SSc patients who did not have SSc-ILD at their first visit were enrolled in the analysis. During the follow-up period, four patients developed SSc-ILD. As shown in Figure 4, there were no significant differences in serum TARC levels between SSc patients who newly developed SSc-ILD during the follow-up period and those who did not $(408.7 \pm 154.6 \mathrm{pg} / \mathrm{mL}$ vs. $388.0 \pm 236.7 \mathrm{pg} / \mathrm{mL}, p=0.538)$. On the other hand, serum KL-6 levels were significantly higher in SSc patients who developed SSc-ILD during the follow- 
up period compared with those who did not $(480.0 \pm 149.5 \mathrm{pg} / \mathrm{mL}$ vs. $264.7 \pm 98.04 \mathrm{pg} / \mathrm{mL}$, $p=0.0011$ ). Similar trends were obtained with serum SP-D levels, but the difference was not statistically significant $(150.5 \pm 117.6 \mathrm{pg} / \mathrm{mL}$ vs. $55.06 \pm 30.06, p=0.078)$. These results suggest that serum TARC levels cannot be used to predict the onset of SSc-ILD.
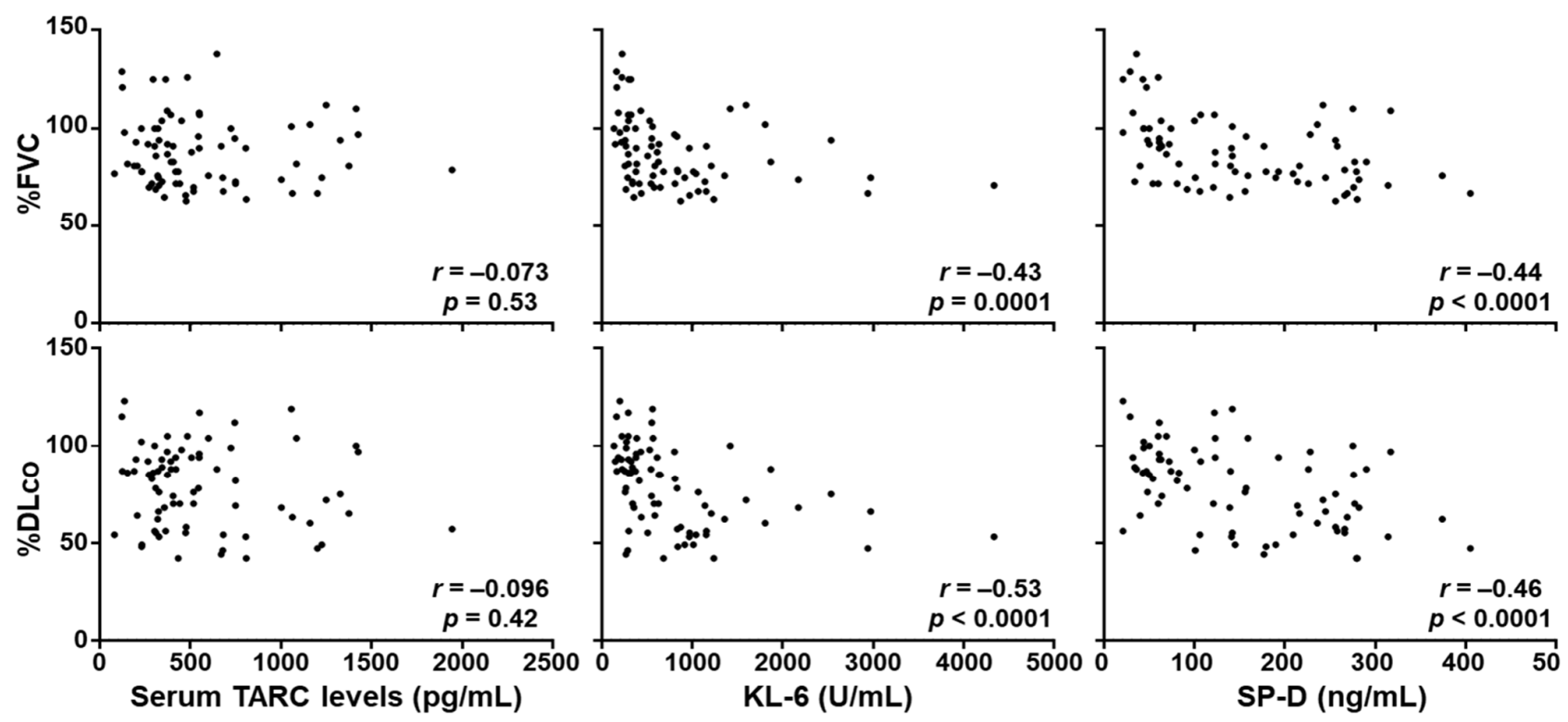

Figure 3. Correlations of serum TARC, KL-6, and SP-D levels with pulmonary function. There were no significant correlations between serum TARC levels and \%FVC or \% DLco. Serum KL-6 and SP-D levels were significantly negatively correlated with \%FVC and \%DLco. Correlations were assessed by Spearman's rank correlation test.
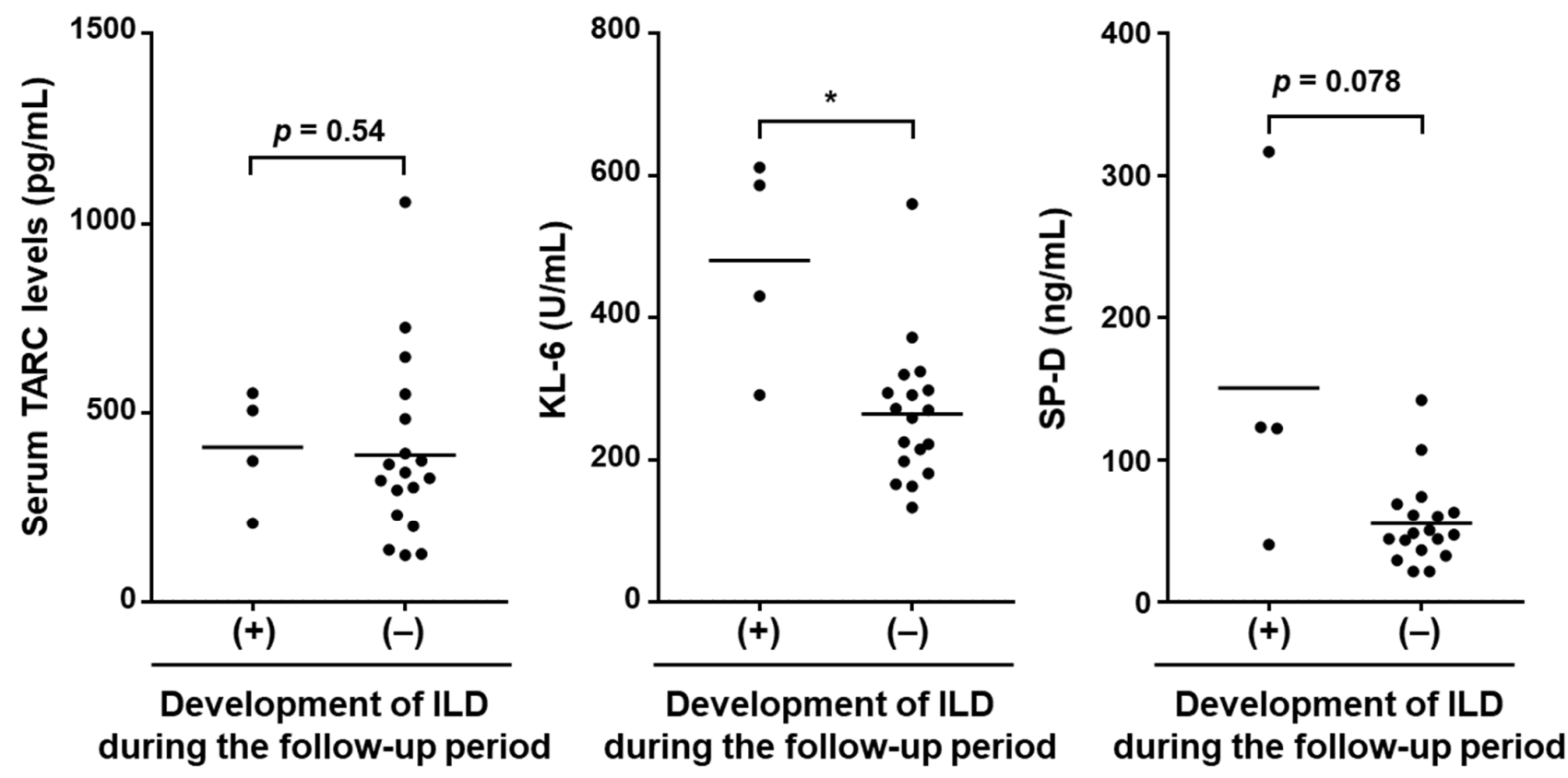

Figure 4. Correlations of serum levels of TARC, KL-6, and SP-D at the first visit with the development of SSc-ILD during the follow-up period. Serum levels of TARC, KL-6, and SP-D levels were analyzed in SSc patients without ILD at their first visit $(n=22)$ and were compared between patients who developed SSc-ILD and those who did not develop SSc-ILD during the follow-up period. Mann-Whitney U-test was performed for two-group comparison. ${ }^{*} p<0.05$. 
3.5. Correlation of Serum TARC Levels at the First Visit and the Progression of SSc-ILD during the Follow-up Period

We further examined whether serum TARC levels in SSc patients at their first visit would predict the progression of SSc-ILD during the follow-up period (Figure 5). For this purpose, 52 SSc patients who had SSc-ILD at their first visit were enrolled in the analysis. There were no significant correlations between serum TARC levels at their first visit and the change of \%FVC or \%DLco during the follow-up period $(r=-0.151, p=0.285$ for $\% \mathrm{FVC}$, $r=0.0777, p=0.584$ for $\% \mathrm{DLco})$. In contrast, there were significant negative correlations between serum KL-6 and SP-D levels at their first visit and the change of \%FVC $(r=-0.672$, $p<0.0001$ for KL-6, $r=-0.491, p=0.0002$ for SP-D) and \%DLco $(r=-0.545, p<0.0001$ for KL-6, $r=-0.523, p<0.0001$ for SP-D) during the follow-up period. These results suggest that serum TARC levels are not a valid predictor for the short-time progression of SSc-ILD.

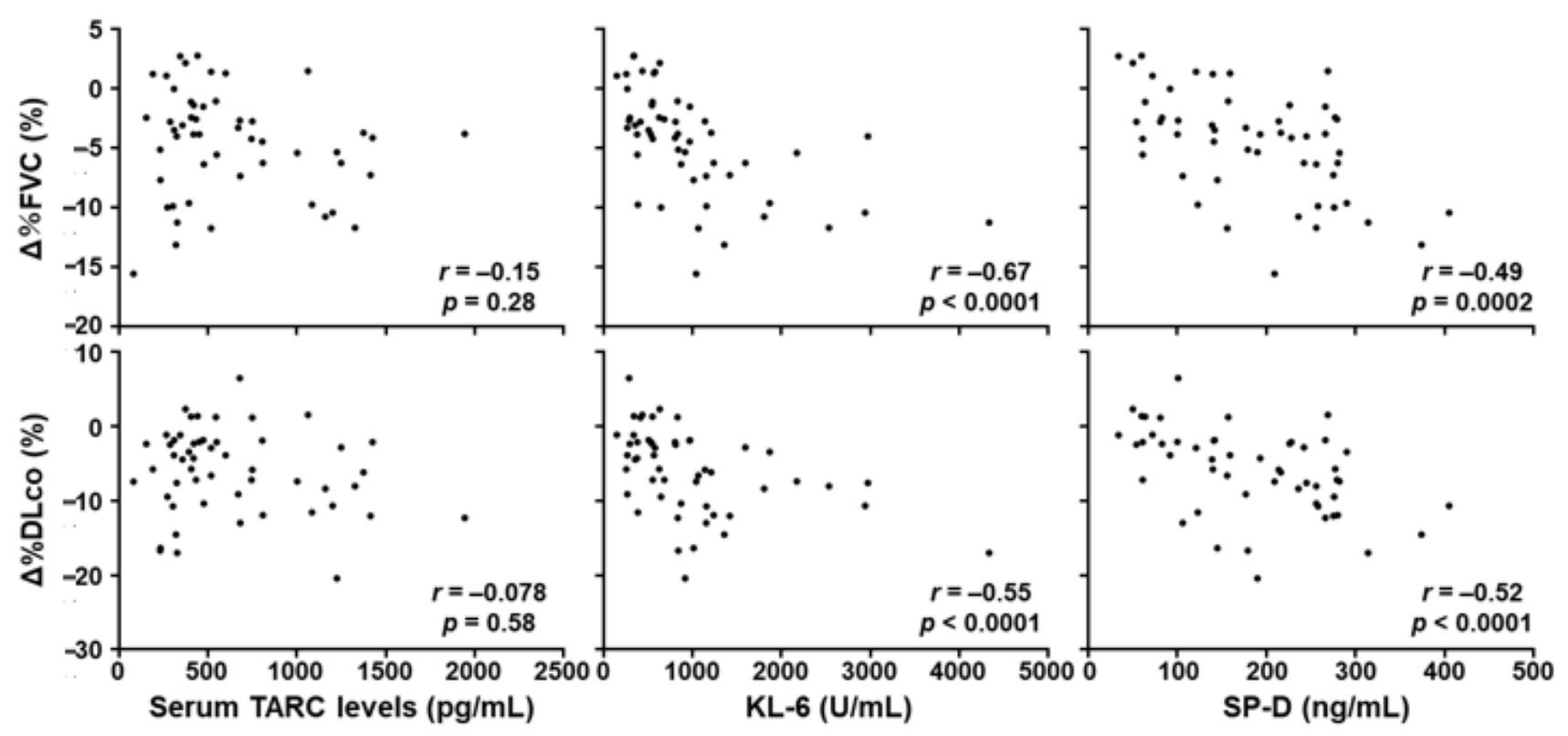

Figure 5. Correlations of serum levels of TARC, KL-6, and SP-D at the first visit with the changes of pulmonary function during the follow-up period. Serum levels of TARC, KL-6, and SP-D levels were analyzed in SSc patients with ILD at their first visit $(n=52)$, and their correlations with the changes of \%FVC and \%DLco after the follow-up period were evaluated. Correlations were assessed by Spearman's rank correlation test.

3.6. Correlation between the Change of Serum TARC Levels and the Progression of SSc-ILD during the Follow-up Period

We also investigated whether the change of serum TARC levels in SSc patients would be correlated with the change of \%FVC and \%DLco during the follow-up period (Figure 6). For this purpose, $52 \mathrm{SSc}$ patients who had SSc-ILD at their first visit were enrolled in the analysis. There were no significant correlations between the change of serum TARC levels and the change of \%FVC or \%DLco during the follow-up period $(r=-0.0132, p=0.926$ for $\% \mathrm{FVC}, r=0.0964, p=0.497)$. In contrast, there were significant negative correlation between the change of serum KL-6 and SP-D levels, and the change of \%FVC $(r=-0.391, p=0.0042$ for KL-6, $r=-0.546, p<0.0001$ for SP-D). Similarly, the change of serum KL-6 and SP-D levels negatively correlated with the change of \%DLco $(r=-0.225, p=0.109$ for KL-6, $r=-0.294, p=0.034$ for SP-D), although the correlation was not statistically significant between the change of KL- 6 and \%DLco. These results suggest that serum TARC levels cannot be used to monitor the disease activity of SSc-ILD. 


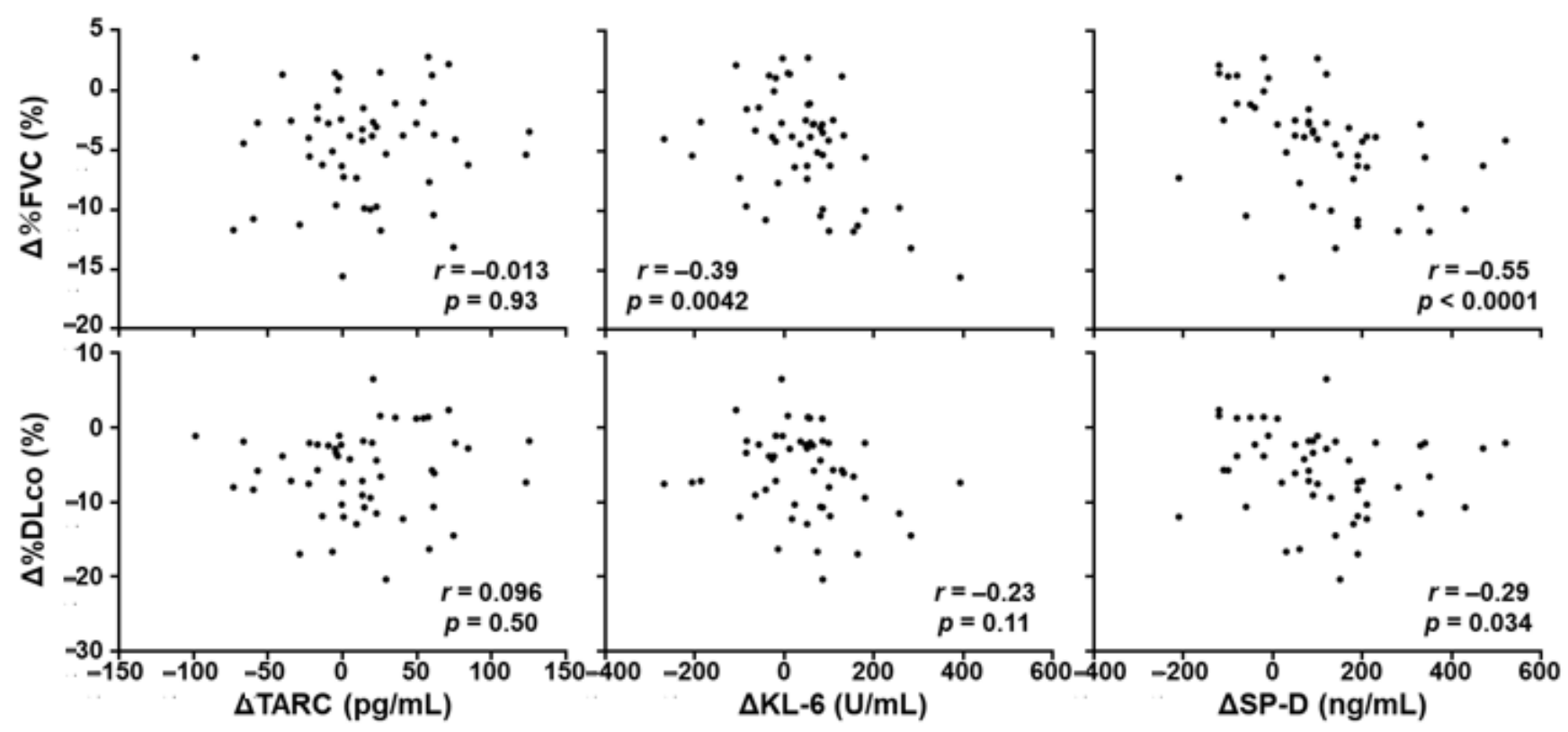

Figure 6. Correlations between the changes of serum TARC, KL-6, and SP-D levels and the changes of pulmonary function during the follow-up period. Correlations between the changes of serum TARC, KL-6, and SP-D levels and the changes of $\%$ FVC and \%DLco during the follow-up period in SSc patients with SSc-ILD at their first visit $(n=52)$. Correlations were assessed by Spearman's rank correlation test.

\section{Discussion}

In this study, we demonstrated that serum TARC levels were significantly elevated in patients with dcSSc compared with healthy controls. Of note, serum TARC levels were significantly higher in SSc patients with ILD than those without ILD. However, there were no significant correlations between serum TARC levels and \%FVC or \%DLco in SSc patients. In the longitudinal analysis, serum TARC levels at the first visit did not predict the onset or progression of SSc-ILD during the short-term follow-up period. Changes of serum TARC levels did not correlate with the changes of \%FVC or \%DLco, either. In contrast, KL-6 and SP-D, the conventional biomarkers for ILD, were well correlated with the onset, severity, and disease activity of SSc-ILD in the same patient population. These results suggest that although elevated serum TARC levels are associated with the presence of SSc-ILD, TARC levels do not correlate with the severity of SSc-ILD, suggesting that TARC cannot be a predictor of fibrotic lesions.

The present study showed that elevated serum TARC levels were associated with higher prevalence of SSc-ILD in patients with SSc. In a previous study, SSc patients with elevated serum TARC levels tended to be more frequently accompanied by SSc-ILD compared with those with normal levels, but it did not reach a statistical significance [28]. The reason for this discrepancy is unclear but may be attributed to the difference in patient population: the overall prevalence of ILD among SSc patients in the previous study was low compared with our study (up to $42 \%$ vs. $70 \%$ ). In addition, the previous study included SSc patients treated with steroids, whereas this study did not. Taken together, our results suggest that elevated serum TARC levels in SSc patients are, at least to some extent, associated with the presence of SSc-ILD.

In SSc, Th2 cells and Th2 cytokines contribute to excessive extracellular matrix deposition by promoting activation and collagen production of fibroblasts both directly and indirectly [10]. A recent study has demonstrated that $\mathrm{T}$ cell differentiation was significantly skewed toward Th2 in patients with SSc-ILD [29]. In line with this, CC chemokine 2 , also known as monocyte chemoattractant protein-1, a chemokine promoting Th2 cell differentiation as well as migration of T cells and monocytes, has emerged as a potential biomarker for SSc-ILD. Serum levels of CC chemokine 2 are significantly correlated with 
the presence and severity of SSc-ILD and also predict the decline of pulmonary function in SSc patients [14]. Although TARC is also critically involved in Th2 immune responses by promoting the migration of Th2 cells, serum TARC levels did not correlate with the onset, severity, or progression of SSc-ILD. Therefore, serum TARC level might not necessarily reflect the pathophysiological process of SSc-ILD, including Th2 immune responses. Indeed, serum TARC levels did not correlate with serum IL-13 levels in SSc patients. However, the pathophysiological process of SSc-ILD is complicated and not limited to Th2 immune responses. For instance, SSc-ILD is associated with IL-8, a neutrophil chemoattractant; CXCL10, a chemoattractant for various immune cells; and CXCL11, a chemoattractant for activated T cells [42-46]. Therefore, evaluating the correlation between serum levels of TARC and these chemokines in SSc patients, especially in dcSSc patients with SSc-ILD, might provide a broader insight into the possible implications of TARC in SSc-ILD. Although further mechanistic studies such as stimulating fibroblasts with TARC are needed to investigate whether and to what extent TARC is involved in SSc-ILD, serum TARC levels do not predict the severity or disease activity of SSc-ILD, which suggests that TARC does not directly cause fibrosis.

In summary, this study examined the serum TARC levels in SSc patients and evaluated their correlation with SSc-ILD. Although elevated serum TARC levels were associated with the presence of SSc-ILD in patients with SSc, serum TARC levels did not correlate with the onset, severity, or progression of SSc-ILD. Although preliminary, this study shows that serum TARC level is not a predictor for assessing the severity or disease activity of SSc-ILD.

\section{Conclusions}

Our data indicate that serum TARC levels were higher in patients with dcSSc compared with healthy controls. In particular, serum TARC levels were elevated in dcSSc patients with SSc-ILD than those without SSc-ILD. However, serum TARC levels did not correlate with the severity or disease activity of SSc-ILD. Furthermore, serum TARC levels cannot predict the onset or the exacerbation of the disease. These results suggest that serum TARC level is not a predictor of disease activity in SSc-ILD, which implies TARC is not necessarily the cause of fibrotic lesions.

Supplementary Materials: The following are available online at https:/ / www.mdpi.com/2077-0 383/10/4/660/s1, Figure S1: Correlation of serum TARC levels with serum IL-13 levels. Table S1: Clinical features of dcSSc patients, Table S2: Clinical features of lcSSc patients.

Author Contributions: Conceptualization, A.K., A.Y., S.E., T.F., A.Y.-O., Y.A., and S.S.; methodology, A.K. and A.Y.; validation, A.K., A.Y., K.O., and S.S.; formal analysis, A.K., A.Y., and K.O.; investigation, A.K.; resources, A.K., A.Y., S.E., T.F., and S.S.; data curation, A.K.; writing-original draft preparation, A.K. and A.Y.; writing-review and editing, A.Y. and S.S.; visualization, A.K.; supervision, S.S.; project administration, S.S.; funding acquisition, A.Y. and S.S. All authors have read and agreed to the published version of the manuscript.

Funding: This research received no external funding.

Institutional Review Board Statement: The study was conducted according to the guidelines of the Declaration of Helsinki and approved by the Ethics Committee of University of Tokyo Hospital (No. 0695 on 11 December 2003).

Informed Consent Statement: Informed consent was obtained from all subjects involved in the study.

Data Availability Statement: The data presented in this study are available on request from the corresponding author. The data are not publicly available due to ethical reasons.

Conflicts of Interest: The authors declare no conflict of interest.

\section{References}

1. Gabrielli, A.; Avvedimento, E.V.; Krieg, T. Scleroderma. N. Engl. J. Med. 2009, 360, 1989-2003. [CrossRef] [PubMed]

2. Yoshizaki, A. Pathogenic roles of B lymphocytes in systemic sclerosis. Immunol. Lett. 2018, 195, 76-82. [CrossRef] [PubMed] 
3. Yoshizaki, A.; Yanaba, K.; Iwata, Y.; Komura, K.; Ogawa, A.; Muroi, E.; Ogawa, F.; Takenaka, M.; Shimizu, K.; Hasegawa, M.; et al. Elevated serum interleukin-27 levels in patients with systemic sclerosis: Association with T cell, B cell and fibroblast activation. Ann. Rheum. Dis. 2011, 70, 194-200. [CrossRef] [PubMed]

4. Kuzumi, A.; Yoshizaki, A.; Toyama, S.; Fukasawa, T.; Ebata, S.; Nakamura, K.; Yamashita, T.; Saigusa, R.; Miura, S.; Hirabayashi, M.; et al. Serum interleukin-34 levels in patients with systemic sclerosis: Clinical association with interstitial lung disease. J. Dermatol. 2018, 45, 1216-1220. [CrossRef]

5. Kalogerou, A.; Gelou, E.; Mountantonakis, S.; Settas, L.; Zafiriou, E.; Sakkas, L. Early T cell activation in the skin from patients with systemic sclerosis. Ann. Rheum. Dis. 2005, 64, 233-1235. [CrossRef] [PubMed]

6. Yoshizaki, A.; Yanaba, K.; Iwata, Y.; Komura, K.; Ogawa, A.; Akiyama, Y.; Muroi, E.; Hara, T.; Ogawa, F.; Takenaka, M.; et al. Cell Adhesion Molecules Regulate Fibrotic Process via Th1/Th2/Th17 Cell Balance in a Bleomycin-Induced Scleroderma Model. J. Immunol. 2010, 185, 2502-2515. [CrossRef]

7. Salmon-Ehr, V.; Serpier, H.; Nawrocki, B.; Gillery, P.; Clavel, C.; Kalis, B.; Birembaut, P.; Maquart, F.X. Expression of interleukin-4 in scleroderma skin specimens and scleroderma fibroblast cultures. Potential role in fibrosis. Arch. Dermatol. 1996, 132, 802-806. [CrossRef]

8. Fuschiotti, P.; Medsger, T.A.; Morel, P.A. Effector $\mathrm{CD}^{+} \mathrm{T}$ cells in systemic sclerosis patients produce abnormally high levels of interleukin-13 associated with increased skin fibrosis. Arthritis Rheum. 2009, 60, 1119-1128. [CrossRef]

9. Hügle, T.; O’Reilly, S.; Simpson, R.; Kraaij, M.D.; Bigley, V.; Collin, M.; Krippner-Heidenreich, A.; van Laar, J.M. Tumor necrosis factor-costimulated T lymphocytes from patients with systemic sclerosis trigger collagen production in fibroblasts. Arthritis Rheum. 2013, 65, 481-491. [CrossRef]

10. O'Reilly, S.; Hügle, T.; van Laar, J.M. T cells in systemic sclerosis: A reappraisal. Rheumatology 2012, 51, 1540-1549. [CrossRef] [PubMed]

11. Rincón, M.; Anguita, J.; Nakamura, T.; Fikrig, E.; Flavell, R.A. Interleukin (IL)-6 directs the differentiation of IL-4-producing CD4 ${ }^{+}$ T Cells. J. Exp. Med. 1997, 185, 461-470. [CrossRef]

12. Khan, K.; Xu, S.; Nihtyanova, S.; Derrett-Smith, E.; Abraham, D.; Denton, C.P.; Ong, V.H. Clinical and pathological significance of interleukin 6 overexpression in systemic sclerosis. Ann. Rheum. Dis. 2012, 71, 1235-1242. [CrossRef]

13. Greenblatt, M.B.; Sargent, J.L.; Farina, G.; Tsang, K.; Lafyatis, R.; Glimcher, L.; Whitfield, M.L.; Aliprantis, A.O. Interspecies Comparison of Human and Murine Scleroderma Reveals IL-13 and CCL2 as Disease Subset-Specific Targets. Am. J. Pathol. 2012, 180, 1080-1094. [CrossRef] [PubMed]

14. Wu, M.; Baron, M.; Pedroza, C.; Salazar, G.A.; Ying, J.; Charles, J.; Agarwal, S.K.; Hudson, M.; Pope, J.; Zhou, X.; et al. CCL2 in the Circulation Predicts Long-Term Progression of Interstitial Lung Disease in Patients With Early Systemic Sclerosis: Data From Two Independent Cohorts. Arthritis Rheum. 2017, 69, 1871-1878. [CrossRef]

15. Mor, A.; Salto, M.S.; Katav, A.; Barashi, N.; Edelshtein, V.; Manetti, M.; Levi, Y.; George, J.; Matucci-Cerinic, M. Blockade of CCL24 with a monoclonal antibody ameliorates experimental dermal and pulmonary fibrosis. Ann. Rheum. Dis. 2019, 78, 1260-1268. [CrossRef] [PubMed]

16. Imai, T.; Yoshida, T.; Baba, M.; Nishimura, M.; Kakizaki, M.; Yoshie, O. Molecular cloning of a novel T cell-directed CC chemokine expressed in thymus by signal sequence trap using Epstein-Barr virus vector. J. Biol. Chem. 1996, 271, 21514-21521. [CrossRef] [PubMed]

17. Imai, T.; Baba, M.; Nishimura, M.; Kakizaki, M.; Takagi, S.; Yoshie, O. The T cell-directed CC chemokine TARC is a highly specific biological ligand for CC chemokine receptor 4. J. Biol. Chem. 1997, 272, 15036-15042. [CrossRef] [PubMed]

18. Saeki, H.; Tamaki, K. Thymus and activation regulated chemokine (TARC)/CCL17 and skin diseases. J. Dermatol. Sci. 2006, 43, 75-84. [CrossRef]

19. Kakinuma, T.; Wakugawa, M.; Nakamura, K.; Hino, H.; Matsushima, K.; Tamaki, K. High level of thymus and activation-regulated chemokine in blister fluid and sera of patients with bullous pemphigoid. Br. J. Dermatol. 2003, 148, 203-210. [CrossRef]

20. Kakinuma, T.; Sugaya, M.; Nakamura, K.; Kaneko, F.; Wakugawa, M.; Matsushima, K.; Tamaki, K. Thymus and activationregulated chemokine (TARC/CCL17) in mycosis fungoides: Serum TARC levels reflect the disease activity of mycosis fungoides. J. Am. Acad. Dermatol. 2003, 48, 23-30. [CrossRef]

21. Vestergaard, C.; Bang, K.; Gesser, B.; Yoneyama, H.; Matsushima, K.; Larsen, C.G. A Th2 chemokine, TARC, produced by keratinocytes may recruit $\mathrm{CLA}^{+} \mathrm{CCR} 4^{+}$lymphocytes into lesional atopic dermatitis skin. J. Investig. Dermatol. 2000, 115, 640-646. [CrossRef] [PubMed]

22. Kakinuma, T.; Nakamura, K.; Wakugawa, M.; Mitsui, H.; Tada, Y.; Saeki, H.; Torii, H.; Asahina, A.; Onai, N.; Matsushima, K.; et al. Thymus and activation-regulated chemokine in atopic dermatitis: Serum thymus and activation-regulated chemokine level is closely related with disease activity. J. Allergy Clin. Immunol. 2001, 107, 535-541. [CrossRef]

23. Ryu, J.H.; Colby, T.V.; Hartman, T.E.; Vassallo, R. Smoking-related interstitial lung diseases: A concise review. Eur. Respir. J. 2001, 17, 122-132. [CrossRef] [PubMed]

24. Fischer, A.; du Bois, R. Interstitial lung disease in connective tissue disorders. Lancet 2012, 380, 689-698. [CrossRef]

25. Yamane, H.; Ochi, N.; Yamagishi, T.; Honda, Y.; Takeyama, M.; Takigawa, N. Circulating thymus and activation-regulated chemokine/CC chemokine ligand 17 is a strong candidate diagnostic marker for interstitial lung disease in patients with malignant tumors: A result from a pilot study. Ther. Clin. Risk Manag. 2015, 11, 949-959. [CrossRef] 
26. Yamane, H.; Ochi, N.; Nagasaki, Y.; Yamagishi, T.; Honda, Y.; Nozomu Nakagawa, N.; Takeyama, M.; Nakanishi, H.; Takigawa, N. Drug-induced interstitial lung disease in the treatment of malignant lymphoma as a potential diagnostic marker: A comparison of serum Krebs von Lungen-6 and thymus and activation-regulated chemokine/CC chemokine ligand 17. Ther. Clin. Risk Manag. 2018, 14, 1457-1465. [CrossRef] [PubMed]

27. Kawashima, T.; Tada, Y.; Asano, Y.; Yazawa, N.; Tomita, M.; Tamaki, Z.; Kubo, M.; Ihn, H.; Sugaya, M.; Kadono, T.; et al. Serum TARC/CCL17 levels are increased in dermatomyositis associated with interstitial lung disease. J. Dermatol. Sci. 2010, 60, 52-54. [CrossRef]

28. Fujii, H.; Shimada, Y.; Hasegawa, M.; Takehara, K.; Sato, S. Serum levels of a Th1 chemoattractant IP-10 and Th2 chemoattractants, TARC and MDC, are elevated in patients with systemic sclerosis. J. Dermatol. Sci. 2004, 35, 43-51. [CrossRef] [PubMed]

29. Boin, F.; De Fanis, U.; Bartlett, S.J.; Wigley, F.M.; Rosen, A.; Casolaro, V. T Cell Polarization Identifies Distinct Clinical Phenotypes in Scleroderma Lung Disease. Arthritis Rheum. 2008, 58, 1165-1174. [CrossRef]

30. Schmidt, K.; Martinez-Gamboa, L.; Meier, S.; Witt, C.; Meisel, C.; Hanitsch, L.G.; Becker, M.O.; Huscher, D.; Burmester, G.R.; Riemekasten, R. Bronchoalveoloar lavage fluid cytokines and chemokines as markers and predictors for the outcome of interstitial lung disease in systemic sclerosis patients. Arthritis Res. Ther. 2009, 11, R111. [CrossRef]

31. Valenzi, E.; Bulik, M.; Tabib, T.; Morse, C.; Sembrat, J.; Bittar, T.H.; Rojas, M.; Lafyatis, R. Single-cell analysis reveals fibroblast heterogeneity and myofibroblasts in systemic sclerosis-associated interstitial lung disease. Ann. Rheum. Dis. 2019, 78, 1379-1387. [CrossRef] [PubMed]

32. Matsushita, T.; Hasegawa, M.; Hamaguchi, Y.; Takehara, K.; Sato, S. Longitudinal analysis of serum cytokine concentrations in systemic sclerosis: Association of interleukin 12 elevation with spontaneous regression of skin sclerosis. J. Rheumatol. 2006, 33, 275-284. [PubMed]

33. Van den Hoogen, F.; Khanna, D.; Fransen, J.; Johnson, S.R.; Baron, M.; Tyndall, A.; Matucci-Cerinic, M.; Naden, R.P.; Medsger, T.A., Jr.; Carreira, P.E.; et al. 2013 classification criteria for systemic sclerosis: An American college of rheumatology/European league against rheumatism collaborative initiative. Ann. Rheum. Dis. 2013, 72, 1747-1755. [CrossRef] [PubMed]

34. LeRoy, E.C.; Black, C.; Fleischmajer, R.; Jablonska, S.; Krieg, T.; Medsger, T.A., Jr.; Rowell, N.; Wollheim, F. Scleroderma (systemic sclerosis): Classification, subsets and pathogenesis. J. Rheumatol. 1988, 15, 202-205.

35. Clements, P.J.; Lachenbruch, P.A.; Seibold, J.R.; Zee, B.; Steen, V.D.; Brennan, P.; Silman, A.J.; Allegar, N.; Varga, J.; Massa, M. Skin thickness score in systemic sclerosis: An assessment of interobserver variability in 3 independent studies. J. Rheumatol. 1993, 20, 1892-1896.

36. Takahashi, T.; Asano, Y.; Yamashita, T.; Nakamura, K.; Saigusa, R.; Miura, S.; Ichimura, Y.; Toyama, T.; Hirabayashi, M.; Taniguchi, T.; et al. A potential contribution of psoriasin to vascular and epithelial abnormalities and inflammation in systemic sclerosis. J. Eur. Acad. Dermatol. Venereol. 2018, 32, 291-297. [CrossRef]

37. Sato, S.; Nagaoka, T.; Hasegawa, M.; Nishijima, C.; Takehara, K. Elevated serum KL-6 levels in patients with systemic sclerosis: Association with the severity of pulmonary fibrosis. Dermatology 2000, 200, 196-201. [CrossRef]

38. Yanaba, K.; Hasegawa, M.; Hamaguchi, Y.; Fujimoto, M.; Takehara, K.; Sato, S. Longitudinal analysis of serum KL-6 levels in patients with systemic sclerosis: Association with the activity of pulmonary fibrosis. Clin. Exp. Rheumatol. 2003, 21, 429-436.

39. Yanaba, K.; Hasegawa, M.; Takehara, K.; Sato, S. Comparative study of serum surfactant protein-D and KL-6 concentrations in patients with systemic sclerosis as markers for monitoring the activity of pulmonary fibrosis. J. Rheumatol. 2004, 31, 1112-1120.

40. Asano, Y.; Ihn, H.; Yamane, K.; Yazawa, N.; Kubo, M.; Fujimoto, M.; Tamaki, K. Clinical significance of surfactant protein D as a serum marker for evaluating pulmonary fibrosis in patients with systemic sclerosis. Arthritis Rheum. 2001, 44, 1363-1369. [CrossRef]

41. Cottin, V.; Brown, K.K. Interstitial lung disease associated with systemic sclerosis (SSc-ILD). Respir. Res. 2019, 18, 13. [CrossRef]

42. Crestani, B.; Seta, N.; Palazzo, E.; Rolland, C.; Venembre, P.; Dehoux, M.; Boutten, A.; Soler, P.; Dombret, M.C.; Kahn, M.F. Interleukin-8 and neutrophils in systemic sclerosis with lung involvement. Am. J. Respir. Crit. Care Med. 1994, 150, $1363-1367$. [CrossRef]

43. Sakamoto, N.; Kakugawa, T.; Hara, A.; Nakashima, S.; Yura, H.; Harada, T.; Ishimoto, H.; Yatera, K.; Kuwatsuka, Y.; Hara, T.; et al. Association of elevated $\alpha$-defensin levels with interstitial pneumonia in patients with systemic sclerosis. Respir. Res. 2015, 16, 148. [CrossRef] [PubMed]

44. Di Luigi, L.; Sgrò, P.; Duranti, G.; Sabatini, S.; Caporossi, D.; Del Galdo, F.; Dimauro, I.; Antinozzi, C. Sildenafil Reduces Expression and Release of IL-6 and IL-8 Induced by Reactive Oxygen Species in Systemic Sclerosis Fibroblasts. Int. J. Mol. Sci. 2020, 21, 3161. [CrossRef] [PubMed]

45. Kameda, M.; Otsuka, M.; Chiba, H.; Kuronuma, K.; Hasegawa, T.; Takahashi, H.; Takahashi, H. CXCL9, CXCL10, and CXCL11; biomarkers of pulmonary inflammation associated with autoimmunity in patients with collagen vascular diseases-associated interstitial lung disease and interstitial pneumonia with autoimmune features. PLoS ONE 2020, 15, e0241719. [CrossRef] [PubMed]

46. Crescioli, C.; Corinaldesi, C.; Riccieri, V.; Raparelli, V.; Vasile, M.; Del Galdo, F.; Valesini, G.; Lenzi, A.; Basili, S.; Antinozzi, C. Association of circulating CXCL10 and CXCL11 with systemic sclerosis. Ann. Rheum. Dis. 2018, 77, 1845-1846. [CrossRef] [PubMed] 